\title{
Prediction of Tomato Yield on the Basis of Solar Radiation Before Anthesis under Warm Greenhouse Conditions
}

\author{
Tadahisa Higashide ${ }^{1}$ \\ National Agricultural Research Center for Western Region, National \\ Agricultural and Food Research Organization, Zentsuji, Kagawa, 765- \\ 0053, Japan
}

Additional index words. Solanum lycopersicum, flower and fruit abortion, fruit number, fruit set, crop productivity model, summer growing season, high temperature

\begin{abstract}
Effects of solar radiation and temperature in different periods before and after anthesis on yield of tomato (Solanum lycopersicum) in summer greenhouse cultivation were investigated. Fluctuations in yield were caused mainly by the variation in fruit number rather than fruit weight. The number of harvested fruit and the yield of plants grown in summer and fall were significantly and positively correlated with solar radiation during the days before anthesis. Although the fruit number and yield were also significantly correlated with air temperature before anthesis, the correlations were weaker than the correlations with solar radiation. There was no significant correlation between the air temperature in the periods encompassing 3 weeks before harvesting and the fruit number and yield. Therefore, fluctuations in fruit number and yield could be predicted by a model based on the solar radiation from 10 to 4 days before anthesis. Validation based on data sets independent of the one used to develop this model showed good correlations between observed and predicted results for plants grown in summer and fall. Thus, solar radiation before anthesis was one of the important factors in prediction of tomato yield under warm greenhouse conditions.
\end{abstract}

In many parts of Japan, it is too hot in the summer to produce tomatoes (Solanum lycopersicum) in a greenhouse without using a special cooling system such as a fog or fan-and-pad system. One of the advantages of hilly and mountainous areas is the cooler summer temperatures caused by the relatively high altitude, which allow greenhouse production of tomatoes during the summer. However, tomato yields fluctuate almost simultaneously in many fields in an area, although the growers, greenhouses, plant growth stages, and crop management differ. Such yield fluctuations cause price fluctuations, a decrease in reliance on the growers, a shift by purchasers to other suppliers, and an inadequate distribution of labor. If fluctuations could be predicted, growers could consider countermeasures such as changing their marketing approaches (e.g., cooperative

\footnotetext{
Received for publication 4 Aug. 2009. Accepted for publication 3 Oct. 2009

This research is part of a research project of Japan's National Agriculture and Food Research Organization, "Vegetable production on sloping lands (2002-2007)."

I thank the tomato growers (Misao Tani, Haruyoshi Kubo, and Osamu Kubo) and their families for their cooperation during this experiment and Ep Heuvelink (Wageningen University) for helpful advice. Current address: National Agriculture and Food Research Organization, Japan, National Institute of Vegetable and Tea Science, 40-1 Minaminakane, Taketoyo, Aichi, Taketoyo, 470-2351, Japan.

${ }^{1}$ To whom reprint requests should be addressed. e-mail ton@affrc.go.jp.
}

shipping with a grower in another area to fill supply gaps) or applying environmental controls in the greenhouse.

Although there have been some reports of successful prediction of tomato yield (Adams, 2002; Heuvelink, 1995), it is difficult to predict the weekly pattern of yield. Yield in single-truss tomato was strongly correlated with total light received from anthesis to harvesting (McAvoy et al., 1989). Hisaeda and Nishina (2007) reported that weekly tomato yields in a commercial greenhouse could be predicted from the cumulative solar radiation for a period from 8 to 1 weeks before harvesting. However, they predicted the yield only in winter and spring to avoid the influence of high temperatures and differences in plant growth stage, although tomatoes are produced almost year-round. Therefore, development of an accurate method to predict weekly fluctuation in tomato yield, especially during summer, is still a big challenge because the yield is determined by several factors such as sink/source ratio, pollen activity, and fruit set.

Studies have been done regarding the effects of high temperature on fruit growth, fruit load, and yield patterns in tomato. De Koning (1989) grew tomato plants at different temperature regimes during the 8 weeks after first flowering, and outside this time period, the plants were grown at the same temperature. He showed that high temperature enhanced early fruit growth at the expense of vegetative growth. The increase in assimilate partitioning to fruit results in reduced leaf growth and increased flower abortion and subsequently delayed fruit growth. Adams and Valdes (2002) recorded increased tomato yields after raising air temperature for 1 week, but subsequently recorded lower yield with no effect on $\mathrm{cu}-$ mulative yield. These reports showed that temperature affects fruit set and development and thus causes yield fluctuations in tomato. Bertin (1995) reported that fruit position and competition for assimilate affected fruit set in tomato. Competition between sinks for assimilate causes yield fluctuations in tomato. There have also been some reports that flower and fruit abortions are caused mainly by a reduction in pollen release resulting from high temperatures before anthesis (Fujii, 1946; Peet et al., 1998; Sato et al., 2000, 2002; Takahashi, 1964).

Shading increases flower and fruit abortions and reduces tomato fruit set (Cockshull et al., 1992; Fujii et al., 1941; Wada et al., 2006). Fruit number is directly influenced by the number of flowers and fruit, by abortion of flowers and fruit, with corresponding effects on yield fluctuations. Tomato yield also reduces by shading after more than 25 d (Gent, 2007), but shading inconsistently affects yield (Russo, 1993).

My goal in this study was to develop a method to predict fluctuations in weekly tomato yield under high temperatures. I investigated the relationships between environmental data and tomato yield and whether these relationships could be used to predict yield fluctuations. These data were obtained from measurements for a popular Japanese tomato cultivar in commercial greenhouses producing tomatoes.

\section{Materials and Methods}

Relationships between yield and environmental data at different periods. The experiment was conducted in two sloped greenhouses belonging to two growers in Higashimiyoshi, Tokushima, Japan (long. $34^{\circ} 00^{\prime} \mathrm{N}$, lat. $\left.133^{\circ} 55^{\prime} \mathrm{E}\right)$. Greenhouses A and B were built on slopes of $20^{\circ}$ facing eastsoutheast and $6^{\circ}$ facing north at elevations of $\approx 355$ and $330 \mathrm{~m}$ above sea level and covered 440 and $284 \mathrm{~m}^{2}$, respectively.

Tomato (S. lycopersicum) cultivar Momotaro 8 (Takii Seed, Kyoto, Japan) was used as the test plant material in this study. In Greenhouses A and B, 1004 and 725 tomato plants were transplanted on $26 \mathrm{Apr}$. and 4 May 2005, respectively. Plant densities in the greenhouses were 2.3 and 2.6 plants $/ \mathrm{m}^{2}$, respectively. A drip fertigation system modified from a soilless culture system (Higashide et al., 2005) was used in Greenhouse A, where plants were grown in soil. A soilless culture system was used in Greenhouse B, where polyethylene bags filled with bark compost were used as the substrate. Both systems were almost the same except for the substrate part.

In both greenhouses, Otsuka-SA nutrient solution (Otsuka Chemical Co., Ltd., Osaka, 
Japan; consisting of $8.8 \mathrm{~mm} \mathrm{NO}_{3}^{-}, 5.1 \mathrm{mM} \mathrm{K}^{+}$, $4.1 \mathrm{mM} \mathrm{Ca}^{2+}, 1.5 \mathrm{mM} \mathrm{Mg}^{2+}, 0.7 \mathrm{~mm} \mathrm{H}_{2} \mathrm{PO}_{4}^{-}$, $3 \mathrm{mg} \cdot \mathrm{L}^{-1}$ iron, $0.05 \mathrm{mg} \cdot \mathrm{L}^{-1}$ manganese, $0.5 \mathrm{mg} \cdot \mathrm{L}^{-1}$ boron, $0.05 \mathrm{mg} \cdot \mathrm{L}^{-1}$ zinc, 0.02 $\mathrm{mg} \cdot \mathrm{L}^{-1}$ copper, and $0.01 \mathrm{mg} \cdot \mathrm{L}^{-1}$ molybdenum) adjusted to 1.2 to $2.5 \mathrm{dS} \cdot \mathrm{m}^{-1}$ was provided to the plants. The nutrient solution supply was controlled by timed switches in both greenhouses. The daily drain percentage was maintained at $20 \%$ to $30 \%$ of the total supply of nutrient solution in Greenhouse B (Higashide et al., 2007a). All plants were pinched at one leaf above the 16th to 18th trusses at the beginning of Oct. 2005. Both greenhouses were cooled by natural ventilation and were not heated. The daily average temperatures remained above $8{ }^{\circ} \mathrm{C}$ throughout the study period and $0.6-\mathrm{mm}$ insect screens and pyriproxyfen tapes (Sumitomo Chemical Co., Ltd., Tokyo, Japan) were used to prevent infestation by whiteflies (Trialeurodes vaporariorum, Bemisia tabaci). To promote fruit set, $15 \mathrm{mg} \cdot \mathrm{L}^{-1}$ of 4-chlorophenoxyacetic acid was sprayed on the lowest three inflorescences and flowers on the fourth to 16 th inflorescences were pollinated by bumble bees (Bombus terrestris).

Truss appearance, number of flowers at flowering, and fruit number at harvesting were observed every week for 10 and 45 plants in Greenhouses A and B, respectively. At each tomato harvest, the total yield (fresh weight) in both greenhouses was determined, but the fruit number was counted in Greenhouse A only. Air temperatures were measured by shaded thermocouples at a height of $150 \mathrm{~cm}$ in the three points of each greenhouse. Outside and inside solar radiation were measured with pyranometer sensors (LI-200SB; LI-COR, Lincoln, NE). These data were recorded at 1-min intervals by data recorders (DX112; Yokogawa Electric Corporation, Tokyo, Japan) in both greenhouses.

The correlations between weekly yield $(Y)$ and the number of fruit harvested $(N)$ and the solar radiation $(S)$ and temperature $(T)$ before and after anthesis were calculated. However, $Y, N, S$, and $T$ have seasonal trends, and the trends in $Y$ and $N$ often follow the trends in $S$ and $T$. Thus, to reduce the influences of the seasonal trends, I defined a volatility statistic for the four parameters. Moving averages for solar radiation $\left(S_{\mathrm{M}}\right)$, temperature $\left(T_{\mathrm{M}}\right)$, weekly yield $\left(Y_{\mathrm{M}}\right)$, and number of fruit $\left(N_{\mathrm{M}}\right)$ for 5 weeks were calculated. The volatility statistic was defined by dividing each parameter by the corresponding moving average $\left(S / S_{\mathrm{M}}, T / T_{\mathrm{M}}\right.$, $Y / Y_{\mathrm{M}}$, and $\left.N / N_{\mathrm{M}}\right)$. As a last step, Pearson's correlation coefficient for $Y / Y_{\mathrm{M}}$ and $N / N_{\mathrm{M}}$ (dependent variables) versus $S / S_{\mathrm{M}}$ and $T / T_{\mathrm{M}}$ (independent variables) was calculated. The statistical software Prism 5 for Windows 5.00 (Graphpad Software Inc., San Diego, CA) was used to analyze the data by Pearson's correlation test, linear and multiple regressions.

Prediction of yield and fruit number. On the basis of the regressions of yield and harvested fruit number with the environmental data, a model for yield prediction was developed.

$$
Y=F\left(S_{1}, S_{2 . .} T_{1}, T_{2 . .} E_{1}, E_{2 . .}\right)
$$

in which $F$, function of $S_{1}, S_{2}, . . T_{1}, T_{2}, . . E_{1}$, $E_{2}, . . ; S_{1}, S_{2}, .$. , solar radiations at the specific periods; $T_{1}, T_{2}, .$. , temperatures at the specific periods; and $E_{1}, E_{2}, .$. , other environmental factors.

Eq. 1 was rearranged based on the relationships between the yield and each of the solar radiation $\left(S_{1}\right)$ and the temperature $\left(T_{1}\right)$ at the period that showed the strongest correlation in the experiment.

$$
Y=F\left(S_{1}, T_{1}, E\right)=f(E) g\left(S_{1}, T_{1}\right)
$$

in which $E$, other environmental factors; $f$, function of $E$; and $g$, function of $S_{1}$ and $T_{1}$.

On the basis of $N / N_{\mathrm{M}}$ and $Y / Y_{\mathrm{M}}$ based on the correlations with $S_{1}$ and $T_{1}$ in Greenhouse $\mathrm{A}$ and $\mathrm{B}$ in 2005, the multiple regression equation was examined.

The fluctuations in yield and fruit number for independent data sets were postpredicted. Data collected from Greenhouses A in 2002 and 2003 and C in 2004 and 2006 were used for validation. Greenhouse $\mathrm{C}$ was built in the same area as the other greenhouses, on a $10^{\circ}$ slope facing east and $\approx 310 \mathrm{~m}$ above sea level, and was $495 \mathrm{~m}^{2}$ in size. The environmental data in Greenhouse $\mathrm{C}$ were measured and recorded every $10 \mathrm{~min}$ by a greenhouse cultivation-support system (Shikoku Instrumentation Co. Ltd., Kagawa, Japan). Plants in all years were grown under the same conditions used in 2005. The yield from all plants in the greenhouse was determined at each harvest. Because the anthesis dates in 2002 and 2003 were not recorded at the lowest five and two inflorescences, respectively, the harvests at those trusses were excluded from validation. All harvests from the end of June to the middle of November in 2004 and 2006 were used for validation, but the fruit number was counted in 2004 only. The anthesis date in 2006 was not recorded, but the date in 2006 was estimated from the linear regression equation in Greenhouses A and B in 2005.

To validate the model based on the correlations between the crop and environ- mental parameters, the predicted weekly fruit number and yield were compared with the observed data and the moving averages of the observed data. The moving averages of fruit number $\left(N^{\prime}\right)$ and yield $\left(Y^{\prime}\right)$ were obtained by using the averages for the period from 3 to 1 weeks before harvesting. Correlations between the predicted fruit number and yield based on the model and the observed data were compared those between the movingaverage $N^{\prime}$ and $Y^{\prime}$ and the observed data.

\section{Results and Discussion}

Relationships between yield and environmental data at different periods. Figure 1 shows the daily average, maximum, and minimum air temperature in Greenhouse B and solar radiation. The solar radiation measured outside the greenhouse fluctuated widely. The daily maximum air temperature was between 21 and $38^{\circ} \mathrm{C}$ at the end of May, increased to $\approx 45{ }^{\circ} \mathrm{C}$ at the beginning of August, and then gradually decreased. The daily minimum air temperature ranged from 16 to $23{ }^{\circ} \mathrm{C}$ during July and August. These temperatures in Greenhouse A were denoted as having almost the same tendencies of those in Greenhouse B (data not shown).

Figure 2 shows the dates of anthesis and harvesting and time from anthesis to harvesting. Anthesis started in the middle of May in both greenhouses. The trusses appeared at a roughly constant rate and the 15th truss reached anthesis by the end of September. Harvesting started at the beginning of July in both greenhouses. The number of harvested trusses increased at a roughly constant rate until the end of September. After this time, the rate of increase in harvested trusses decreased. Time from anthesis to harvesting increased from $\approx 40$ for anthesis at the end of July to between 70 and 80 for anthesis at the beginning of September.

Total yield and percentage of Grade A fruit in the market in Greenhouses A and B were 15.5 and $14.1 \mathrm{~kg} \cdot \mathrm{m}^{-2}$ and $77 \%$ and $98 \%$, respectively (data not shown; Higashide et al., 2007b). The weekly yield was strongly correlated with the number of fruit harvested in Greenhouse A $(r=0.95, P<0.001)$, but the

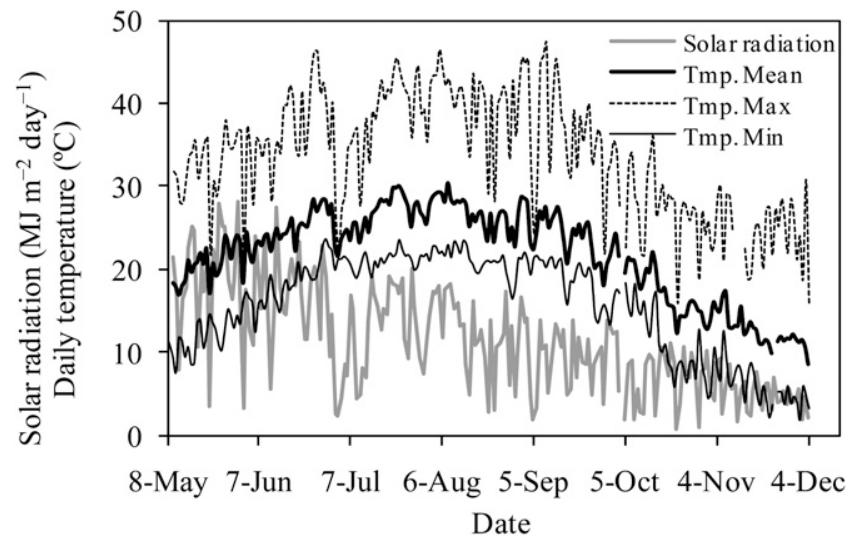

Fig. 1. Daily average, maximum, and minimum air temperatures in Greenhouse B and solar radiation outside the greenhouse during the experimental period (2005). 
fruit number was not recorded in Greenhouse B. However, there was no correlation between the weekly yield and weight per fruit; the fruit weight in Greenhouse A averaged $130 \pm 46 \mathrm{~g}$ /fruit (mean $\pm \mathrm{SD}$ ). Therefore, changes in weekly yield were caused mainly by changes in fruit number rather than changes in fruit weight.

Table 1 shows the correlations between the different periods before or after anthesis for the volatility of solar radiation and the two crop parameters (weekly yield and fruit number). I used moving averages for solar radiation $(S)$ in 7-d intervals encompassing from $14 \mathrm{~d}$ before anthesis through $4 \mathrm{~d}$ after anthesis. All correlations with $S / S_{\mathrm{M}}$ at each interval to $Y / Y_{\mathrm{M}}$ and $N / N_{\mathrm{M}}$ were examined except those during the first week of harvesting because harvesting started in the middle of that week.

$Y / Y_{\mathrm{M}}$ and $N / N_{\mathrm{M}}$ were both significantly correlated with $S / S_{\mathrm{M}}$ at the different periods encompassing 12 to $0 \mathrm{~d}$ before anthesis in both greenhouses, except in the case of $Y / Y_{M}$ from 6
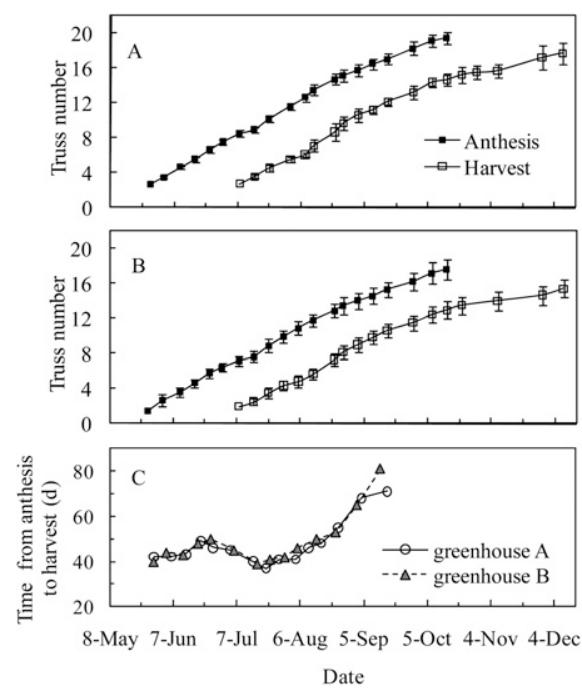

Fig. 2. Date of anthesis and harvesting for tomatoes grown in Greenhouses A (A) and B (B) and time from anthesis to harvesting $(\mathbf{C})$ in 2005. Values in $\mathbf{A}$ and $\mathbf{B}$ are means \pm SD $(\mathrm{n}=10$ and 45 , respectively). to $0 \mathrm{~d}$ before anthesis in Greenhouse A. The correlation coefficients from 10 to $4 \mathrm{~d}$ before anthesis were highest in both greenhouses for both parameters ( $r=0.59$ to $0.65, P<0.01$ ). There was no significant correlation between either parameter and $S / S_{\mathrm{M}}$ after anthesis.

Because the correlations between solar radiation and the two crop parameters (yield and fruit number) were strongest for the period from 10 to $4 \mathrm{~d}$ before anthesis in both greenhouses, I used that as the period to further examine the relationship. Figure 3 shows the weekly yield and number of fruit harvested and average solar radiation from 10 to $4 \mathrm{~d}$ before anthesis. The weekly yield fluctuated between levels greater than 1.0 $\mathrm{kg} \cdot \mathrm{m}^{-2} /$ week until roughly mid-July to less than $0.6 \mathrm{~kg} \cdot \mathrm{m}^{-2} /$ week by October in both greenhouses. The fluctuations in the weekly yield and fruit number frequently coincided with the fluctuations in the average solar radiation from 10 to $4 \mathrm{~d}$ before anthesis.

$Y / Y_{\mathrm{M}}$ and $N / N_{\mathrm{M}}$ were also significantly correlated with the volatility of temperature $\left(T / T_{\mathrm{M}}\right)$ from $10 \mathrm{~d}$ before to $2 \mathrm{~d}$ after anthesis in both greenhouses ( $r=0.46$ to $0.63, P<0.03$ ) with the exception of $Y / Y_{\mathrm{M}}$ depending on temperature from $6 \mathrm{~d}$ before through $2 \mathrm{~d}$ after anthesis in Greenhouse A (Table 2). These correlations were weaker than the correlations with the volatility of solar radiation, possibly because $T / T_{\mathrm{M}}$ was significantly correlated with $S / S_{\mathrm{M}}$ in both greenhouses $(r=0.71$ to $0.83, P<$ $0.01)$. There was no significant correlation between either crop parameter and $T / T_{\mathrm{M}}$ for the periods from 3 to 0 weeks ( 21 to $1 \mathrm{~d}$ ) before harvesting. Thus, the fluctuations in fruit number and yield could be predicted by fluctuations in solar radiation and temperature during the period encompassing 12 to $0 \mathrm{~d}$ before anthesis

In this experiment, conducted under high temperatures, sink strength was likely to have been high because the plants had many fruit as a result of the high rate of truss appearance and rapid fruit development (Fig. 2). Much of the photoassimilate would have been partitioned into these fruit rather than into flowers. Bertin (1995) reported that strong competition for assimilates (i.e., strong sink strength) negatively affects fruit set in tomato. De Koning (1989) showed that high temperature promotes fruit growth in tomato at the ex-

Table 1. Pearson's correlation coefficient $(r)$ for the relationships between volatility of solar radiation $\left(S / S_{\mathrm{M}}\right)$ at different periods before and after anthesis and weekly yield $\left(Y / Y_{\mathrm{M}}\right)$ and fruit number $\left(N / N_{\mathrm{M}}\right)$ of tomatoes.

\begin{tabular}{lcccc}
\hline & \multicolumn{4}{c}{ Correlation $(r)^{\mathrm{z}}$ between $S / S_{\mathrm{M}}$ and } \\
\cline { 2 - 5 } Period & $\mathrm{A}, 2005^{\mathrm{y}}$ & $\mathrm{B}, Y_{\mathrm{M}}$ & \multicolumn{2}{c}{$N / N_{\mathrm{M}}$} \\
\cline { 2 - 5 } & 0.23 & 0.29 & $\mathrm{~A}, 2005$ & $\mathrm{~B}, 2005$ \\
\hline 14 to 8 DBA & $0.49^{*}$ & $0.47^{*}$ & 0.20 & $-{ }^{\mathrm{x}}$ \\
12 to 6 DBA & $0.59^{* *}$ & $0.63^{* *}$ & $0.65^{* * *}$ & - \\
10 to 4 DBA & $0.52^{*}$ & $0.54^{* *}$ & $0.60^{* *}$ & - \\
8 to 2 DBA & 0.40 & $0.43^{*}$ & $0.48^{*}$ & - \\
6 to 0 DBA & 0.17 & 0.14 & 0.33 & - \\
4 DBA to 2 DAA & -0.26 & -0.09 & -0.14 & - \\
2 DBA to 4 DAA & & & - \\
\hline
\end{tabular}

zPearson's correlation coefficient, except in the first week of harvesting. *, **, and *** indicate significance at the $0.05,0.01$, and 0.001 levels, respectively.

${ }^{\mathrm{y}}$ Greenhouse and year.

No data.

DBA $=$ days before anthesis; DAA $=$ days after anthesis. pense of vegetative growth. These results suggest that increased partitioning of photoassimilate to the fruit increased flower abortion. Because there are fewer numbers of fruit as a result of flower abortion, high temperature increases fruit weight. Lower light levels (i.e., lower source activity) caused by shading also reduce fruit set and yield (Cockshull et al., 1992; Gent, 2007; Russo, 1993; Wada et al., 2006). Solar radiation in this experiment fluctuated widely (Fig. 1), so source activity would also have fluctuated widely. A decrease in solar radiation would temporarily decrease photosynthate availability (i.e., would reduce source activity), and the resulting high sink-to-source ratio would decrease fruit set. Meiosis has been reported as the most critical stage for tomato pollen development, which occurs several days before anthesis (Iwahori, 1965). Although there was no direct evidence, source activity during the most critical period for fruit set, which would be strongly related to the strength of the solar radiation several days before anthesis, would in turn be correlated with fruit number.

Previous research has shown that the period from 15 to $8 \mathrm{~d}$ before anthesis is the critical period during which high temperatures could influence fruit set in tomato (Fujii, 1946; Peet et al., 1998; Sato et al., 2000, 2002; Takahashi, 1964). In light of these reports, a negative correlation between fruit number and temperature before anthesis has been assumed. However, no negative correlation between fruit number and temperature fluctuations before anthesis was observed; the volatility of fruit number and yield were both significantly and positively correlated with the volatility of temperature before anthesis (Table 2) as was the case for solar radiation (Table 1), because temperature was strongly correlated with solar radiation. The minimum air temperature in this area was relatively low and ranged from 16 to $23{ }^{\circ} \mathrm{C}$ during the high-temperature season (Fig. 1). The effect of high temperature on fruit set could be alleviated by lower temperature immediately after anthesis as reported by Sato et al. (2002).

Adams (2002) reported that the weekly yield of tomatoes could be predicted by the relationship between fruit development stage and temperature. Adams and Valdes (2002) reported that high temperature before harvesting accelerated the ripening of fruit that were in their final maturation stage. This temporarily increased the number of fruit harvested and subsequently decreased this number but did not affect cumulative yield. However, these temperature effects in the present experiment were not observed; there was no significant correlation between fluctuations in fruit number and yield and fluctuations in temperature for the periods from 3 to 0 weeks before harvesting. This is because both the average and maximum temperatures during my experiment were higher than those in these two previous studies. The effects of high temperature before harvesting on the yield could be prominently shown during the low-temperature season in this area. 
Prediction of fruit number and yield. $S / S_{M}$ from 10 to $4 \mathrm{~d}$ before anthesis $\left(S_{1}\right)$ and $T / T_{M}$ from 8 to $2 \mathrm{~d}$ before anthesis $\left(T_{1}\right)$ that showed the strongest correlation in Tables 1 and 2, respectively, were used as parameters on the model (Eq. 2). The regression equation for $Y /$ $Y_{M}$ was obtained as whole data in both greenhouses because there was no significant difference in each regression in Greenhouses $\mathrm{A}$ and $\mathrm{B}$.

$$
\begin{aligned}
g_{N}\left(S_{1}, T_{1}\right)= & N / N_{\mathrm{M}}=0.74 S_{1}+3.26 T_{1} \\
& -3.00\left(r^{2}=0.47\right) \\
g_{Y}\left(S_{1}, T_{1}\right)= & Y / Y_{\mathrm{M}}=0.98 S_{1}+0.74 T_{1} \\
& -0.083\left(r^{2}=0.36\right)
\end{aligned}
$$

in which ${ }_{N}$, number of fruit; and $Y$, yield.
Eqs. 3 and 4 were significant $(P<0.01)$; however, the explanatory variables of $T_{1}$ in the equations were not significant $(P=0.17$ and 0.7 , respectively). Thus, $T_{1}$ was removed from the model.

$$
\begin{gathered}
g_{N}\left(S_{1}\right)=N / N_{\mathrm{M}}=1.182 S_{1}-0.193 \\
\left(r^{2}=0.42\right) \\
g_{Y}\left(S_{1}\right)= \\
\quad Y / Y_{\mathrm{M}}=1.082 S_{1} \\
-0.083\left(r^{2}=0.36\right)
\end{gathered}
$$

Predicted weekly fruit number $\left(N_{\mathrm{P}}\right)$ and yield $\left(Y_{\mathrm{P}}\right)$ were obtained from Eqs. 5 and 6 and $f_{N}(E)$ and $f_{Y}(E)$; those were assumed the moving average of fruit number $\left(N^{\prime}\right)$ and fruit yield $\left(Y^{\prime}\right)$ during 3 to 1 weeks before harvesting, respectively.
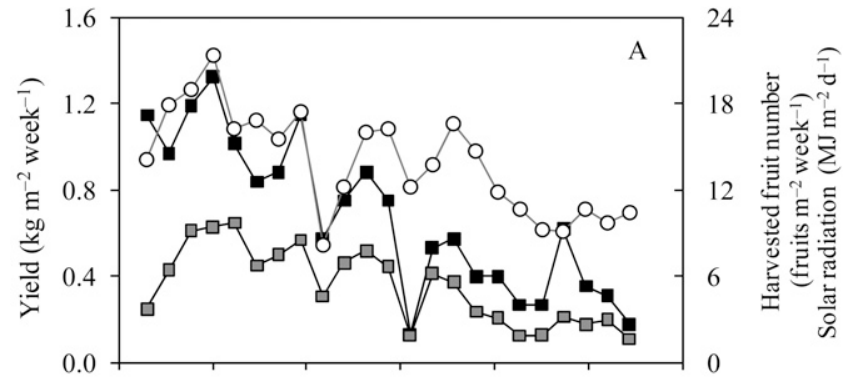

\begin{tabular}{|c|c|c|c|c|}
\hline \multirow[b]{3}{*}{ Period } & \multicolumn{4}{|c|}{ Correlation $(r)^{\mathrm{z}}$ between $T / T_{\mathrm{M}}$ and } \\
\hline & \multicolumn{2}{|c|}{$Y / Y_{M}$} & \multicolumn{2}{|c|}{$N / N_{\mathrm{M}}$} \\
\hline & $\mathrm{A}, 2005^{\mathrm{y}}$ & B, 2005 & A, 2005 & B, 2005 \\
\hline 14 to $8 \mathrm{DBA}$ & 0.04 & 0.16 & 0.12 & $-^{x}$ \\
\hline 12 to $6 \mathrm{DBA}$ & 0.35 & 0.18 & 0.21 & - \\
\hline 10 to $4 \mathrm{DBA}$ & $0.52 *$ & $0.47 * *$ & $0.53 * *$ & - \\
\hline 8 to $2 \mathrm{DBA}$ & $0.48^{*}$ & $0.59 * *$ & $0.63 * *$ & - \\
\hline 6 to $0 \mathrm{DBA}$ & 0.27 & $0.62 *$ & $0.52 *$ & - \\
\hline $4 \mathrm{DBA}$ to $2 \mathrm{DAA}$ & 0.18 & $0.46^{*}$ & $0.52 *$ & - \\
\hline $2 \mathrm{DBA}$ to $4 \mathrm{DAA}$ & 0.08 & 0.21 & 0.41 & - \\
\hline 21 to $15 \mathrm{DBH}$ & 0.31 & 0.00 & 0.21 & - \\
\hline 14 to $8 \mathrm{DBH}$ & 0.05 & 0.28 & 0.11 & - \\
\hline 7 to $1 \mathrm{DBH}$ & 0.27 & 0.23 & 0.14 & - \\
\hline
\end{tabular}

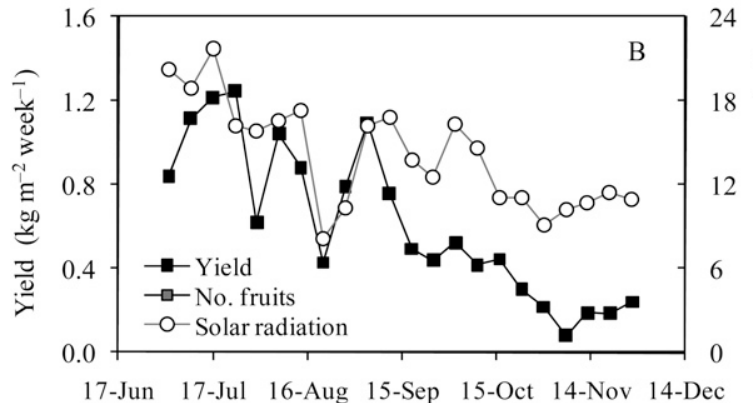

Harvest date

Fig. 3. Weekly yield, weekly number of tomatoes harvested, and average daily solar radiation from 10 to 4 $\mathrm{d}$ before anthesis in Greenhouses A (A) and B (B) in 2005.

Table 2. Pearson's correlation coefficient $(r)$ for the relationships between volatility of temperature $\left(T / T_{M}\right)$ at different period before and after anthesis and weekly yield $\left(Y / Y_{\mathrm{M}}\right)$ and fruit number $\left(N / N_{\mathrm{M}}\right)$ of tomatoes.

HortScience Vol. 44(7) December 2009

$$
\begin{aligned}
N_{\mathrm{P}}= & f_{N}(E) g_{N}\left(S_{1}\right)=N^{\prime}\left(1.182 S_{1}\right. \\
& -0.193) \\
Y_{\mathrm{P}}= & f_{Y}(E) g_{N}\left(S_{1}\right)=Y^{\prime}\left(1.082 S_{1}\right. \\
& -0.083)
\end{aligned}
$$

The weekly fruit number and yield predicted using Eqs. 7 and 8 were compared with the observed data and the moving-average $N^{\prime}$ and $Y^{\prime}$ values based on the data sets in 2002 , 2003, 2004, and 2006. The predicted fruit number and yield from Greenhouse C in 2004 often fluctuated simultaneously with fluctuations in the observed data (Fig. 4). The predicted fruit number and yield were lower than those of the observed during the first several weeks, because the prediction was based on $N^{\prime}$ and $Y^{\prime}$ as the moving averages during 3 to 1 week before harvesting that were low during a few weeks after the harvesting started.

The model (Eqs. 7 and 8), based on the product of fruit number and yield approximated by using the volatility of solar radiation before anthesis, provided high prediction accuracy (Table 3 ). The correlations between the predicted fruit number and yield and the observed data except for 2006 were stronger than those between the movingaverage and the observed data, respectively. The correlation between the predicted yield and the observed data in 2006 was almost the same as that between the moving-average and the observed data. Thus, the model would be helpful for predicting increases or decreases in fruit number and yield. The model is suitable for practical use, because it is easy to record the anthesis date and record the volatility of the solar radiation. Therefore, growers could use this model to predict their crop yields and thus take appropriate
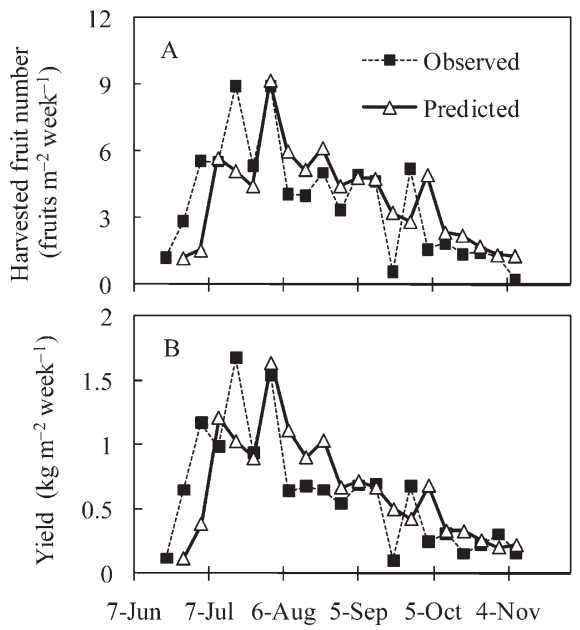

Harvest date

Fig. 4. Comparison of weekly fruit number (A) and yield (B) of tomatoes predicted from Eqs. 7 and $8^{z}$ with the observed number of fruit harvested and yield in Greenhouse C in 2004. ${ }^{\text {z}}$ See the section "Prediction of fruit number and yield" in Results and Discussion. 
Table 3. Pearson's correlation coefficient ( $r$ ) for the relationships between observed data and each of predicted yield and fruit number of tomatoes, and moving averages from 3 to 1 weeks before harvesting.

\begin{tabular}{lccc}
\hline & & \multicolumn{2}{c}{$\begin{array}{c}\text { Correlation }(r) \text { between } \\
\text { observed data and }\end{array}$} \\
\cline { 3 - 4 } Year & & $0.60^{*}$ & $0.69^{* *}$ \\
\hline 2002 & Yield & $0.80^{* *}$ & $0.84^{* * *}$ \\
2003 & Yield & $0.63^{* *}$ & $0.77^{* * *}$ \\
2004 & No. fruit & $0.67^{* *}$ & $0.80^{* * *}$ \\
2004 & Yield & $0.55^{*}$ & $0.56^{*}$ \\
2006 & Yield & Poving avg & Prediction \\
\hline$*, * *$ & and $* * *$ & indicate & significance at the 0.05, \\
0.01, and 0.001 levels, respectively. &
\end{tabular}

countermeasures in response to large fluctuations. In addition, if the prediction models for fruit number and yield could be improved by incorporating a model of dry matter accumulation, the predictions would become even more accurate.

In conclusion, fluctuations in the weekly fruit number and yield for tomatoes grown in greenhouses during the summer and fall were strongly and significantly correlated with fluctuations in solar radiation during the periods encompassing 12 to $0 \mathrm{~d}$ before anthesis. Therefore, on the basis of fluctuations in solar radiation, fluctuations in fruit number and yield under these conditions could be predicted. Validation of my models using independent data sets in 4 years showed strong agreement between the observed and predicted fruit number and yield values. Thus, solar radiation at the period before anthesis was one of the important factors in prediction of tomato yield under warm greenhouse conditions.

\section{Literature Cited}

Adams, S.R. 2002. Predicting the weekly fluctuations in greenhouse tomato yields. Acta Hort. 593:19-23.

Adams, S.R. and V. Valdes. 2002. The effect of periods of high temperature and manipulating fruit load on the pattern of tomato yields. J. Hort. Sci. Biotechnol. 77:461-466.

Bertin, N. 1995. Competition for assimilates and fruit position affect fruit set in indeterminate greenhouse tomato. Ann. Bot. (Lond.) 75:55-65.

Cockshull, K.E., C.J. Graves, and C.R.J. Cave. 1992. The influence of shading on yield of glasshouse tomatoes. J. Hort. Sci. 67:11-24.

De Koning, A.N.M. 1989. The effect of temperature on fruit growth and fruit growth load of tomato. Acta Hort. 248:329-336.

Fujii, T. 1946. Research on flower abscission of tomato. No. 3. Effect of high temperature. Studies Hort. Sci. 3:12-28 [in Japanese].

Fujii, T., Y. Toita, and Y. Inako. 1941. Research on flower abscission of tomato. No. 1. Effect of light condition. Agr. Hort. 16:1600-1604 [in Japanese].

Gent, M.P.N. 2007. Effect of degree and duration of shade on quality of greenhouse tomato. HortScience 42:514-520.

Heuvelink, E. 1995. Dry matter production in a tomato crop: Measurements and simulation. Ann. Bot. (Lond.) 75:369-379.

Higashide, T., T. Ibuki, Y. Kasahara, and T. Kinoshita. 2007a. Control of nutrient solution supply to tomato plants grown in a soilless culture system suitable for use on sloping land. Acta Hort. 761:567-571.

Higashide, T., T. Ibuki, Y. Kasahara, O. Sumikawa, T. Sakoda, and T. Kinoshita. 2007b. Cultivation of tomato in a sloped greenhouse by a fertigation system suitable for use on sloping land. Hort. Res. (Jpn.) 6:91-95 [in Japanese with English abstract].

Higashide, T., Y. Kasahara, T. Ibuki, and O. Sumikawa. 2005. Development of closed, energy-saving hydroponics for sloping land. Acta Hort. 691:243-248.

Hisaeda, K. and H. Nishina. 2007. Studies on improvement of tomato productivity in a largescale greenhouse-Prediction of tomato yield based on integrated solar radiation. J. Sci. High Technol. Agr. 19:11-18 [in Japanese with English abstract].

Iwahori, S. 1965. High temperature injuries in tomato. IV. Development of normal flower buds and morphological abnormalities of flower buds treated with high temperature. J. Jpn. Soc. Hort. Sci. 34:33-41.

McAvoy, R.J., H.W. Janes, B.L. Godfriaux, M. Secks, D. Duchai, and W.K. Wittman. 1989. Effect of total available photosynthetic flux on single truss tomato growth and production. J. Hort. Sci. 64:331-338.

Peet, M.M., S. Sato, and G. Gardner. 1998. Comparing heat stress effects on male-fertile and male-sterile tomatoes. Plant Cell Environ. 21: 225-231.

Russo, V.M. 1993. Shading of tomato plants inconsistently affects fruit yield. HortScience 28:680-684.

Sato, S., M.M. Peet, and J.F. Thomas. 2000. Physiological factors limit fruit set of tomato (Lycopersicon esculentum Mill.) under chronic, mild heat stress. Plant Cell Environ. 23:719726.

Sato, S., M.M. Peet, and J.F. Thomas. 2002. Determining critical pre- and post-anthesis periods and physiological processes in Lycopersicon esculentum Mill. exposed to moderately elevated temperatures. J. Expt. Bot. 53: 1187-1195.

Takahashi, K. 1964. High temperature effect on fruit vegetables. Agr. Hort. 39:803-806 [in Japanese]

Wada, T., H. Ikeda, K. Matsushita, A. Kambara, H. Hirai, and K. Abe. 2006. Effects of shading in summer on yield and quality of tomatoes grown on a single-truss system. J. Jpn. Soc. Hort. Sci. 75:51-58. 